\title{
'Age-Related' Versus 'Motivational' Factors in Second/Foreign Language Learning: Some Evidence from Immigrant Learners of English as a Second Language'
}

\author{
Dr Thembinkosi E. Mabila \\ Language Education - English, University of Limpopo, Turfloop Campus, South Africa \\ Thembinkosi.Mabila@ul.ac.za
}

\section{Doi:10.5901/mjss.2014.v5n23p1340}

\begin{abstract}
In this article, Age related factors in second and foreign language learning were examined to determine the extent to which Lenneberg's (1967) Critical Period Hypothesis (CPH) applies to immigrants in multilingual communities. To achieve this purpose, two groups of students (namely, learners of Mozambican origin and South African locals) were selected to conduct a quantitative study on English second language proficiency as well as integrative motivation. The results obtained in the two groups were correlated in order to determine if integrative motivation played a role in the ultimate attainment of Mozambican immigrants in English second language. The results showed that the Mozambican learners learned English at a faster rate that their South African counterparts. However, this fast rate did not correlate positively with the learners' integrative motivation as was expected. The article therefore concludes that, for immigrants in multilingual societies, some other factor other that the $\mathrm{CPH}$ may explain the fast rate at which the immigrant group learned English.
\end{abstract}

Keywords: Language Learning; Age; Critical period; lateralization; immigrants

\section{Introduction}

Research on age-related factors in second-language acquisition (SLA) has for decades been rooted in the Critical Period Hypothesis (CPH) initiated by Lenneberg (1967). Age-related differences expounded in the CPH (also referred to in this article simply as the Neurolinguistic Theory) are grounded in the assumption of a biological mechanism in the brain thought to be responsible for the abilities to acquire, know, and use further languages. The hypothesis, proposed to account for first language (L1) recovery in aphasics, claims that there is a biologically determined period, the "critical period", beyond which language acquisition becomes difficult or even impossible, as a result of language lateralization of the left hemisphere of the brain. Although it was formulated in relation to primary or first-language (L1) acquisition, the hypothesis, however, fleetingly refers to SLA, too. In L2, the hypothesis has been reinforced by the observation that younger learners, in spite of their slow pace in L2 acquisition, become more proficient, especially in pronunciation (see Krashen, Long and Scarcella, 1979), than older, post-puberty learners. This may explain, in part, the trend worldwide towards an early start in the teaching and learning of foreign languages (Nikolov, 2000) to ensure holistic language competence.

However, the Neurolinguistic Theory, which posits a biological mechanism affecting SLA, has since been seriously challenged (Munoz, 2010; Carrió-Pastor \& Mestre, 2013). Critics have either expressed scepticism about, or rejected, the theory out of hand on methodological or empirical grounds. Even among supporters of the $\mathrm{CPH}$, opinions are divided between a strong version of $\mathrm{CPH}$, closer to Lenneberg's initial formulation, and a weak version (Schouten, 2009).

One of the underlying arguments against the neurolinguistic theory factor which has often been overlooked in the debate is that learning a further language is a complex process, a fact which Hull $(1992$, p77) believes, is "the clearest thing in our current state of knowledge" about SLA. Consequently, learning ought not to be thought of as solely a function of biological factors. Problems associated with the learning of a further language may be related to: the features of languages coming into play, for instance; the primary and the target languages; features of the learner him/herself, cognitive (Krashen, 1982) or affective (Schumann, 1975); and factors related to the environment of learning situation (Vaseghi \& Barjesteh, 2012). With reference to environmental factors, much of the research based on age differences has been conducted in essentially monolingual societies, with a fairly simple linguistic map applicable to education and may not apply to highly multilingual societies with a more complex language-in-education structure (Mabila, 2001). In this respect, Birdsong (1992) suggests that we consider the idea of differential levels of attainment in a further language as relative to each specific experimental context. 
My awareness of the impact of environmental factors on SLA and impressionistic evidence of successful learning of English as a second language (ESL) in South Africa by post-pubertal Mozambican immigrants prompted the study reported in this article. The discussion of the $\mathrm{CPH}$ has concerned the rate and the proficiency or attainment level. In the case of these immigrant ESL learners, who speak Changana and Portuguese and start learning English only after arriving in the L2 land, South Africa, at the close of the critical period, a logical prediction based on the CPH would be that their L2 land counterparts would fare significantly better in English, having started learning it before the onset of puberty. This is true since it is believed elsewhere that the existence of a $\mathrm{CPH}$ for second language acquisition (SLA) would have serious implications for older learners (Qingxin, 2012). Yet, my classroom observations and interaction with school authorities in the settlement area of these immigrants suggested that immigrant learners sometimes outperformed their L2 land classmates. This perplexing observation was the spur to the empirical study reported in this article.

The central question which the study sought to answer was: To what extent do age-related and motivational factors influence the acquisition of ESL by Mozambican immigrant learners? This question was grounded in the assumptions that: (i) Mozambican immigrant learners would lag behind their L2 land counterparts in the level of ESL; and (ii) immigrant learners who were strongly integratively motivated would at best reach the level of ESL proficiency comparable to that of their L2 land counterparts.

Before outlining the study and discussing the results, I shall review briefly two sets of competing theories, namely: neuro-linguistic theories, represented by the $\mathrm{CPH}$, and sociolinguistic theories instantiated by the Acculturation Model.

\section{Neurolinguistic vs. Sociolinguistic Explanations of SLA}

The brief mention of the effect of age-related factors on SLA, most especially the completion of the brain lateralization, prompted immense interest among SLA researchers. Indeed, the extent to which age-related features impacted on SLA is both theoretically important and pedagogically crucial for planning language programmes and language pedagogy responsive to the age of second-language learners (Kubota, 1999). Among important issues are those of the rate and the proficiency or attainment level between prepubescent and post-puberty L2 learners (Obler \& Hannigan, 1996). It is, thus, generally postulated that, if the biological constraints resulting from brain lateralization can be extrapolated to SLA, the learning of a secondary language started after puberty will probably be incomplete. This position is generally held by proponents of what has been referred to by Ritchie and Bhatia (1996, p693) as the "Global Critical Period Hypothesis" closer to Lenneberg's initial hypothesis. The Global Critical Period Hypothesis represents the strong version of the Neurolinguistic Theory. It states that brain lateralization affects all aspects of language acquisition.

The $\mathrm{CPH}$ has had its critics. One of the criticisms levelled against the $\mathrm{CPH}$ is that it seems to be only true of one area of language acquisition, which is pronunciation (Schouten, 2009). It fails to explain why plasticity, the biological change of the brain used to explain the difficulty of acquiring an L2 after puberty, only affects pronunciation. Three other criticisms have been on the methodology used to obtain much of the evidence on brain plasticity and the differential hemispheres of the brain (Kovelman, Baker \& Petitto, 2008). Firstly, most of the earlier evidence on which age-related factors of SLA came from clinic work on brain-damaged or speech-impaired children and adults. Secondly, experimental and quasi-experimental studies of the effect of age on L2 learning have been carried out over too short periods of time to be of much value. Thirdly, such experiments tend to be selectively focused on relatively small aspects of the target language.

A closer and systematic critical examination of the $\mathrm{CPH}$ resulted in weaker versions, or refinements of the $\mathrm{CPH}$. Among these are: (i) the proposal of the existence of "multiple critical periods" [my italics] (Seliger, 1978), the preference for one "sensitive period" (Lamendella, 1977), and (iii) the hypothesis of "multiple sensitive periods" [my italics] (Long, 1990). These theoretical claims do not, however, represent a single view, but different strands of the Sensitive Period Hypothesis, a revised form of Lenneberg's CPH. I outline each theoretical strand of the refined CPH.

Initial revisions of the CPH shared Seliger's (1978) suggestion of the existence of multiple critical periods on the basis of ultimate achievement at adulthood of child L2 learners and of development sequence (see Schacter, 1996 for a discussion of ultimate achievement; and Schwartz, 1992, for a discussion of developmental sequence). The view supporting the existence of multiple critical periods assumes the existence of differential maturational constraints which operate on different language skills (phonological, morpho-syntactic, and semantic). For example, pronunciationreferred to by some as "accent"(Ritchie \& Bhatia, 1996) has demonstrably been found to be typically correlated with childhood (Oyama, 1976, 1978), whereas morphosyntax is much more greatly acquired at pre-puberty (Patkowski, 1980).

In the process, researchers suggested that L2 acquisition was subject to a "sensitive period", rather than a "critical period" (Lamendella, 1977, p15). The sensitive period is seen as less rigid than a critical period (Schafer, 2009). It is a window of sensitivity to the learning process, which is understood in terms of "increased sensitivity" from and "decreased 
sensitivity" into periods of less sensitivity. In contrast, the critical period is a fixed period which seems to start at a given point and ends somehow abruptly. Indeed, the $\mathrm{CPH}$ assumes that beyond this period, acquisition is impossible because latelarization is completed. This may explain the phenomenon of "fossilization" (De Bot \& Larsen Freeman, 2011) or "incompleteness" (Han \& Odlin, 2006) is possible.

It must be pointed out, however, that despite the suggestion of "a sensitive period", it is the contemporaneous notion of "multiple critical periods" that held its ground. It eventually lost ground and was superseded by the idea of "multiple sensitive periods" (Granena, 2013). The latter are different periods, presumably longer than critical periods, during which the acquisition of different aspects of the target language is more likely to occur and after which this possibility declines significantly to the point that acquisition is only random. Therefore the strict boundaries posited by the $\mathrm{CPH}$ and its strong version are softened by the suggestion that there exist periods of heightened sensitivity or responsiveness to particular environments, which increase and decrease from periods of lesser sensitivity which respectively precede and follow them (see also Schacter, 1996). Similarly, the idea of one single "sensitive period" is no longer seen as relevant, given evidence of differential levels of attainment of different aspects of language at different ages.

Aside from the modifications of the $\mathrm{CPH}$, other SLA scholars, in accounting for the impact on target language attainment of "internal factors", or factors associated with features of the learner, have, however, emphasized social-psychological factors. A case in point is the Acculturation Model (Schumann, 1978a, 1978b, 1978c). This model proposes that the degree to which a learner integrates and interacts socially with the speakers of the target language influences the success of his or her acquisition of the target language. The learners' levels of social and psychological distance between themselves and the target group determine acculturation. Here Schumann concurs with Gardner's (1985) as well as Gardner and Lambert's (1972) contention that integrative motivation facilitates acquisition and a higher level of attainment. What is referred to as the Acculturation Hypothesis states that where the levels of social (or psychological) distance with native speakers of the language are low, acculturation will occur, and this will then lead to successful acquisition of the target language (Lybeck, 2002). The observation of a higher level of social or psychological distance will lead to unsuccessful or partial acquisition of the target language (Barjesteh \& Vaseghi, 2012).

The model has been challenged by the results of a longitudinal study with a Japanese L1 speaker who was learning English in the US who, despite having shown low social and psychological distance from the target culture, did not acquire grammatical competence significantly different from his initial level three years earlier (see Schmidt 1983). Schumann's model is called into question only as far as the development of grammatical competence goes because considerable development was noticed in the subject in discourse, strategic, and sociolinguistic competence.

All in all, Schumann's model still has a lot of credence since he himself claims that it accounts for language learning under conditions of immigration. In South Africa, English is the dominant language among the eleven official languages. It is the "language of power, prestige, and status" (Kamwangamalu, 2001:81). One indication of this hegemonic position occupied by English, especially in education, is the trend among parents, including Afrikaans-speaking families (see de Klerk, 2001), to send their children to English-medium schools. Hence, the model is very relevant to immigrants learning a L2 in the South African context, such as to the case of Mozambican immigrants who require the knowledge of English for integration purposes.

\section{The Study: Design, Instruments, Sampling, and Procedure}

Five main tasks were planned in the study to answer the main research of the study, namely, to: (i) measure the grammatical, textual, illocutionary, and sociolinguistic proficiency of South African and Mozambican learners; (ii) to establish the age of first exposure to English of the South African and Mozambican learners; (iii) compare the ESL proficiency of the South African and Mozambican learners, and interpret their respective levels of proficiency in the light of the age of first exposure; (iv) measure the integrative motivation of the Mozambican learners; and (v) correlate the ESL proficiency scores and the integrative motivation scores of the Mozambican learners.

To fulfill these objectives, a quantitative design was chosen in which a multiple-choice question test, in accordance with Bachman and Palmer's (2010) model of language competence as well as a questionnaire were administered to South African and Mozambican high school learners. The test was used to measure ESL competence. A first draft of the questionnaire was pilot-tested on 17 Grade 11 learners, eight of whom were of Mozambican origin, nine South African-born. The ages of the respondents ranged from 17 to 27 years. The final questionnaire was used to collect demographic information (including biological age as well as age of first exposure to English) and motivational (integrative and instrumental) data. This component of the questionnaire included 20 items in the form of self-report, half of them semantic differential questions, the other closed-ended, multiple choice, and questions. In the semantic differential items, 
the respondents were required to compare the usefulness of acquiring English for various reasons by rating each reason with regard to five different qualities. The ratings indicated on the five scales were added up, and the totals thereof were correlated with their level of ESL proficiency. In the multiple-choice part, the responses were coded as falling into three categories, each of which was assigned one of three possible scores. The respondents were given the opportunity to express themselves freely by writing their comment on by saying anything that they thought would improve their ESL proficiency

The use of the questionnaire was preferred to other data-gathering tools for three reasons. Firstly, it was deemed to be more cost-efficient than other techniques, such as the interview. Secondly, the questionnaire would permit anonymity, thus increasing the chances of receiving responses that would genuinely represent the respondents' beliefs and feelings. Thirdly, it had the potential to provide greater uniformity across measurement situations than would the interview.

The study used 59 Grade 12 respondents, 25 female, and 34 male. Thirty-one of them were of Mozambican origin, the other 28 were South African born. All were learners at a secondary school in the Nkomazi district of the Mpumalanga province of South Africa. The school is about 30 kilometres away from the Mozambican border, in an area overwhelmingly populated by Mozambican immigrants. The area is relatively poor economically, as is the school in terms of resources.

Stratified sampling was used to include both male and female Mozambican and South African learners. The questionnaire and ESL proficiency test were administered at the school during the ESL periods with the assistance of one teacher. The teacher also acted as an informant and assisted in the coding of the scripts. A precaution was taken to ensure suitable seating arrangements and low-noise background. The usual instructions that all pupils expect to hear at the start of a test were given and work proceeded as in a normal class test. Both the researcher and the class teacher remained in the classroom throughout the administration of the test until the last script was collected.

The data were analysed through descriptive statistics. The ESL proficiency test scores for the two groups were tabulated and compared. Thereafter a correlational analysis was applied to the Mozambican immigrants' second language scores and their results for the measure of integrative motivation. The results for the data analysis are discussed in the next section.

\section{Results and Discussion of the Findings}

\subsection{Age-related differences}

Table 1: Demographic data (averages and standard deviations)

\begin{tabular}{lcc}
\hline & Group A & Group B \\
\hline Average age & $19.6[2.1]$ & $19.9[1.4]$ \\
Average age of first exposure & $8.4[2.4]$ & $11.5[.8]$ \\
Average years of learning & $11.1[1.9]$ & $8.4[1.7]$ \\
\hline
\end{tabular}

Note: Group A= South African respondents; Group B= Mozambican respondents

It was found that average age of the South African respondents (19.6 years) and that of the Mozambicans respondents (19.9 years) were not significantly different (although the Mozambican respondents were fractionally older on average than their South African counterparts). The age was, therefore, not a significant variable likely to bias the conclusions. As expected, there was a significant gap (of three years) between the age of first exposure of the South African sample (at 8.4 years of age) and that of their Mozambican counterparts, who were first exposed to English about three years later (at a bout the age of 11.5 years). The Mozambicans were, therefore, first exposed at about the age of the onset of puberty, or rather at the close of a period in which SLA happens 'less easily'. Besides, they had been learning English at school for approximately three years less than their South African classmates. This difference in years of learning was statistically significant, as shown in Table 2 below. 
Table 2: Average age differences

\begin{tabular}{ccc}
\hline & Group A & Group B \\
\hline Mean & 11.1 & 8.4 \\
Std dev & 1.9 & 1.7 \\
$N$ & 28 & 31 \\
\hline F-test & & \\
df & & 27.3 \\
F & 1.3 & \\
p & & \\
$t$-test & 57 & \\
df & & \\
t & & \\
p & & 5.7 \\
\hline
\end{tabular}

Note: Group A= South African respondents; Group B= Mozambican respondents

As a measure of verification, an F-test was used to determine the equality of variance of the two samples in order or not to perform a $t$-test. The result of the $F$-test $(F=1.2 ; p=.250 ; d f=27.3)$ shows that the variance was sufficiently equal for a $t$-test to be performed meaningfully. A t-tested was, then, performed to measure the significance of the difference between the average number of years of learning English for the South African and Mozambican samples. The result of the $t$-test $(t=5.72 ; p=<0.001 ; d f=57)$ shows that the difference in the number of years of learning for the South African and Mozambican learners is statistically significant. The age-related literature assumes that the initial exposure is an important factor in the development of competence and attainment level in the target language. In the present case, such a significantly low number of years of learning of English for the Mozambican sample would likely negatively affect their L2 acquisition. More concretely, according to the $\mathrm{CPH}$, the Mozambican learners who only became exposed to English at around puberty could not attain the same levels of proficiency as the South African learners of the same age who were exposed to English from a much younger age.

The results of the ESL proficiency test, for each of the four questions and for the overall proficiency, are summarised and presented in Table 3 below.

Table 3: ESL proficiency results (Averages and standard deviations)

\begin{tabular}{ccccccc}
\hline & & Q.1 & Q.2 & Q.3 & Q.4 & Totals \\
\hline Group A & Average & 4.2 & 2.1 & 3 & 2.8 & 12.1 \\
& Std dev & 1.6 & 1 & 0.8 & 1.4 & \multirow{2}{*}{ Group B } \\
& Average & 4.1 & 1.8 & 2.4 & 2.8 & 1 \\
\hline & Std dev & 1.6 & 1 & 1 & 1.2 & \\
\hline
\end{tabular}

Note: Group A= South African respondents; Group B= Mozambican respondents

As may be seen from the data presented in Table 3 above, the overall ESL proficiency of Mozambican (11.16) and South African (12.07) respondents was almost the same, more especially so on three of the four types of questions, namely: questions measuring grammatical (Q. 1), textual (Q. 2), and sociolinguistic (Q. 4) competence. Submitted to a $t$-test for a measure of significance of the difference between the average ESL proficiency results for both groups of learners, the results ( $t=0.99 ; p=0.38 ; d f=57$ ) show no significant difference in the overall ESL proficiency. There seems to be, however, a difference between the two groups of learners in illocutionary competence (Q. 3) that is "how to make meaning out of words and utterances". South African learners scored significantly higher for this skill than their Mozambican counterparts, as shown in Table 4 below. 
Table 4: Scores for illocutionary competence

\begin{tabular}{|c|c|c|}
\hline & Group A & Group B \\
\hline Mean & 3 & 2.4 \\
\hline Std dev & .9 & 1 \\
\hline $\mathrm{N}$ & 28 & 31 \\
\hline$F$-test & \multicolumn{2}{|c|}{30.3} \\
\hline $\mathrm{df}$ & \\
\hline $\mathrm{F}$ & \multicolumn{2}{|c|}{1.5} \\
\hline$p$ & \multicolumn{2}{|c|}{.15} \\
\hline$t$-test & \multicolumn{2}{|c|}{57} \\
\hline$d f$ & & \\
\hline $\mathrm{t}$ & \multicolumn{2}{|c|}{2.4} \\
\hline$p$ & \multicolumn{2}{|c|}{$<.018$} \\
\hline
\end{tabular}

Note: Group A= South African respondents; Group B= Mozambican respondents

It is not clear why the length of exposure and the initial age of exposure could have a significant impact on illocutionary competence, and not on the other three types of competence. One explanation may be that, unlike other areas of language competence, illocutionary competence requires the specification of "context" and/or the introduction of presupposition for which South African testees may have had an edge over their Mozambican co-testees.

The lateralisation of the functions of the brain into the different hemispheres which is completed at puberty presumably slows the acquisition of a target language considerable some time before puberty and ultimately stops it completely at puberty. In other words, the Mozambican learners who started learning English shortly before puberty, for less time than their South African counterparts, would likely have a level of competence far lower than the latter and far short of the basic English language competence. The results of the present study, however, reject this prediction: the Mozambican immigrants display, through the test administered, the same overall level of English proficiency as their South African counterparts.

Given this unexpected result, the identification of other factors than initial age of learning, which is posited by the $\mathrm{CPH}$, and the length of learning, was necessary. One assumption was that the $\mathrm{CPH}$ may reflect ethnocentric thinking. Indeed, formulated on the basis of studies conducted in pervasively monolingual societies, it may have limited applicability in highly multilingual contexts. In the latter contexts, learning may be facilitated or hindered significantly by other clusters of variables, one of which is motivation. In the next section a presentation and an analysis of the data on motivation are provided, and an interpretation of the results is offered.

\subsection{Motivation explanation}

Two items in the questionnaire were used to measure the Mozambican immigrants' strength of integrative motivation. Indeed, it was assumed that the unexpected higher level of proficiency, given their initial age of learning and the length of exposure to English, might be facilitated by a high level of integrative motivation, the desire to learn a language to "integrate" in the target-language environment (see Gardner and Lambert, 1972). The results on motivation are presented in Table 5 below.

Table 6: Integrative motivation

\begin{tabular}{cccc}
\hline & Q.5 & Q.6 & Total \\
\hline Average & -.7 & 5.5 & 4.8 \\
Std dev & 4.4 & 2.6 & 5.1 \\
\hline
\end{tabular}

For both items, a negative score indicates a stronger instrumental motivation, while a positive score indicates a stronger integrative motivation. Out of a possible score of 20 (for the two questions combined), the average total for the group of immigrant learners is 4.8 . As table 6 shows, the main finding in this category indicates that generally the strength of integrative motivation is low for the Mozambican immigrants.

In the hope that a positive relationship between the motivation (in this case, integrative) and ESL performance within this group, a correlation of the Mozambican immigrants' age and ESL proficiency scores was measured to determine the strength of the possible linear relationship between the variables. The matrix of correlation co-efficients 
shown in table 7 indicates no significant relationship.

Table 7: Correlation co-efficients

\begin{tabular}{ccccccc}
\hline & Age & Q.1 & Q.2 & Q.3 & Q.4 & Totals \\
Q7 & 0.08 & -0.14 & -0.19 & -0.39 & -0.15 & \\
Q6 & 0.37 & -0.26 & 0.05 & 0.05 & 0.02 & \\
MOT & 0.26 & -0.25 & -0.14 & -0.31 & -0.14 & -0.31 \\
\hline
\end{tabular}

As the summary of the findings in table 7 shows, the finding was that for this group of learners, there is no linear relationship between the fast rate of ESL acquisition and integrative motivation for the Mozambican immigrants. Therefore, some other factor(s) other than integrative motivation may explain the increased rate of ESL acquisition by the Mozambican immigrants. For instance, Gömleksiz (2001) points to the level of cognitive development, socio-economic and cultural background whilst Jaspal (2010) points to a 'weakened sense' of identity (such as when learners were raised in a bilingual household).

\section{Conclusion}

Generally, the findings of this study reinforced the idea that age does not always negatively affect the acquisition of language. Hence it is true, the success in second language acquisition depends on many factors. Indeed, age and motivation factors are among the most important ones. However, in multilingual societies such as the location of the current study, it is also true that if a learner has a competency in his or her own language, he or she is more advantageous than those who have not completed their first language. Hence, in this article, I come to agreement with Schouten (2009, p. 9) who indicates that "using age effects as an explanation for ultimate attainment in a second language is overly simplistic and insufficient". Secondly, from the results of the study reported in this article, it can be inferred that integrative motivation plays a crucial role in the ultimate attainment of learners of a second language. But, based on my experience with the Mozambican immigrants reported in this article, it can be concluded that where other factors such as the multilingual environment are at play, very little can be attributed to acculturation and integrative motivation. This could be especially so, in the light of the fact that there may be "various degrees of similarity between the languages of different immigrants and the language of their destination country" (Isphording \& Otten, 2014, p30).

\section{References}

Bachman, L. (1990). Fundamental considerations in language testing. Oxford: Oxford University Press.

Barjesteh, H. \& Vaseghi, R. (2012). Acculturation model for L2 acquisition: Review and evaluation. Advances in Asian social sciences 2(4), $579-584$.

Beebe, L. M. (Ed.). (1988). Issues in second language acquisition. Boston: Heinle \& Heinle Publishers.

Birdsong, D. (1992). Ultimate attainment in second language acquisition. Language 68(4), 706-755.

Carrió-Pastor, M.L. \& Mestre, E.M. (2014). Motivation in Second Language Acquisition. Procedia - Social and Behavioral Sciences 116, $240-244$

De Bot, K. \& Larsen-Freeman, D. (2011). Researching second language development from a dynamic systems theory perspective. In M.H. Verspoor, K de Bot, \& W. Lowie (Eds.), A dynamic approach to second language development: Methods and techniques (pp. 5 - 24). Amsterdam: John Benjamins

De Klerk, V. (2001). 'What am I doing to my child?' Moving to English schools. In E. Ridge, S. Makoni and S.G.M. Ridge (Eds.), Freedom and discipline. Essays in applied linguistics from Southern Africa (pp. 105-128). New Delhi: Bahri Publications.

Gardner, R. \& W. Lambert (1972). Attitudes and motivation in second language learning. Rowley, MA: Newbury House.

Gardner, R. (1985). Social psychology and second language learning: The role of attitudes and motivation. London: Edward Arnold.

Gömleksiz, M.N. (2001). The effect of age and motivation factors on second language acquisition. Firat University Journal of social science 11(2), 217-224.

Granena, G. (2013). Reexamining the robustness of aptitude in second language acquisition. In G. Granena \& M. Long (Eds.), Sensitive periods, language aptitude, and ultimate L2 attainment (pp. 179 - 204). Amsterdam: John Benjamins.

Han, Z. \& Odlin, T. (2006). Studies of fossilization in second language acquisition. Ontario. Multilingual Matters Ltd.

Hull, J.C. (1992). The learner-centered classroom: Is there a role for role play? Perspective (Working papers of the Department of English, City Polytechnic of Hong Kong) 4(2): 77-87.

Isphording, I.E. \& Otten, S. (2014) Linguistic barriers in the destination language acquisition of immigrants. Journal of economic behavior \& organization 105, $30-40$.

Jaspal, A. (2010). Second language acquisition. Innervate 2, 235-246. 
Kamwangamalu, N.M. (2001). Ethnicity and language crossing in post-apartheid South Africa. International Journal of the sociology of language 152, 75-95.

Kovelman, I., Baker, A.A., \& Petitto, L. (2008). Bilingual and monolingual brains compared: A functional magnetic resonance imaging investigation of syntactic processing and a possible "neural signature" of bilingualism. Journal of cognitive neuroscience 20(1), 153-169.

Krashen, S. (1982). Accounting for child-adult differences in second language rate and attainment. In S. Krashen, R. Scarcella and M. Long (Eds.), Child-adult differences in second language acquisition (pp. 202-226). Rowley, MA: Newbury House.

Krashen, S.D., M. Long \& R. Scarcella (1979). Age, rate, and eventual attainment in second language acquisition. TESOL Quarterly 13(3), 573-582.

Kubota, R. (1999). Japanese culture constructed by discourses: Implications for applied linguistics research and ELT. TESOL Quarterly 33(1), 9-37.

Lamendella, J.T. (1977). General principles of neurofunctional organization and their manifestation in primary and nonprimary language acquisition. Language learning 27(1), 155-196.

Lenneberg, E. (1967). Biological foundations of language. New York: Wiley and Sons.

Long, M.H. (1990). Maturation constraints on language development. Studies in second language acquisition 12(2), 251-285.

Lybeck, K. (2002). Cultural identification and second language pronunciation of Americans in Norway. Modern language journal, 86 (2), 174-191.

Mabila, T.E. (2001). Age, integrative motivation and English second language proficiency amongst Mozambican immigrants in Mpumalanga. Unpublished Mini-Dissertation, University of the North: Sovenga.

Munoz, C. (2010). On how age affects foreign language learning. Advances in Research on Language Acquisition and Teaching, $39-49$. Retrieved from http://www.enl.auth.gr/gala/14th/Papers/Invited\%20Speakers/Munoz.pdf

Nikolov, M. (2000). The critical period hypothesis reconsidered: Successful adult learners of Hungarian and English. International review of applied linguistics in language teaching 38(2), 109-124.

Obler, L.K. \& S. Hannigan (1996). Neurolinguistics of second language acquisition and use. In W.C. Ritchie \& T.K. Bhatia (Eds.), Handbook of second language acquisition (pp. 509-523). San Diego: Academic Press.

Oyama, S (1976). A sensitive period for the acquisition of a nonnative phonological system. Journal of Psycholinguistic Research 5, 261283.

Oyama, S. (1978). The sensitive period and comprehension of speech. Working papers on bilingualism 16, 1-17.

Patkowski, M. (1980). The sensitive period for the acquisition of syntax in a second language. Language learning 30(2), $449-472$.

Qingxin, Z. (2012). Is there a critical period for second language acquisition. IPCSIT 43, 1-5.

Ritchie,W.C. \& T.K. Bhatia (Eds.). (1996). Handbook of second language acquisition. San Diego: Academic Press.

Schacter, J. (1990). On the issue of completeness in second language acquisition. Second Language Research 6(2), 93-124.

Schacter, J. (1996). Maturation and the issue of universal grammar in second language acquisition. In W.C. Ritchie, \& T.K. Bhatia (Eds.), Handbook of second language acquisition (pp. 158-193). San Diego: Academic Press.

Schafer, D.R (2009). Social and personality development. Belmont: Wadswoth Cengage Learning

Schmidt, R. (1983). Interaction, acculturation and the acquisition of communicative competence: A case study of an adult. In N. Wolfson and E. Judd (Eds.), Sociolinguistics and language acquisition (pp. 137-174). Rowley, MA: Newbury House.

Schouten, A. (2009). The critical period hypothesis: Support, challenge, and reconceptualization. Working papers in TESOL \& Applied linguistics, 9(1), 1- 16.

Schumann, R. (1978a). The acculturation model for second language acquisition. In R. Gingras (Ed.), Second language acquisition and foreign language teaching (pp. 27-50). Arlington, VA: Center for Applied Linguistics.

Schumann, R. (1978b). The pidginization process: A model for second language acquisition. Rowley, MA: Newbury House.

Schumann, R. (1978c). The relationship of pidginization, creolization, and decreolization to second language acquisition. Language learning, 28, 367-379.

Schwartz, B.D. (1992). Testing between UG-based and problem-solving models of L2 A. Developmental sequence data. Language acquisition 2:1-19.

Seliger, H. (1978). Implications of a multiple period hypothesis for second language learning. In W. Ritchie (Ed.), Second language acquisition research (pp. 11-19). New York: Academic Press. 